\title{
O CONHECIMENTO SOBRE SEXUALIDADE - POR UMA GNOSIOLOGIA (TEORIA DO CONHECIMENTO) EM EDUCAÇÃO SEXUAL: ALGUMAS INDAGAÇÕES
}

\author{
CONOCIMIENTO SOBRE SEXUALIDAD - PARA UMA GNOSIOLOGÍA (TEORÍA \\ DEL CONOCIMIENTO) EM LA EDUCACIÓN SEXUAL: ALGUNAS PREGUNTAS
}

\author{
KNOWLEDGE ABOUT SEXULITY - FOR A GNOSIOLOGY (THEORY OF \\ KNOWLEDGE) IN SEXUAL EDUCATION: SOME QUESTIONS
}

Claudionor Renato da SILVA ${ }^{1}$

RESUMO: O(s) conhecimento(s) das pessoas, sobre sexualidade, na área da Educação Sexual (ES), muitas vezes, é apenas ponto de partida para pesquisas ou formações continuadas para professores(as), mas quase inexistentes são as propostas de transformação em teoria e, posterior construção de currículo em ES, destes conhecimentos. Diante disso, o presente artigo, de metodologia bibliográfica, pretende propor o referencial da gnosiologia/teoria do conhecimento (G/TC), enfatizando as formas diversas de se conhecer sobre sexualidade. Depois de um breve referencial em G/TC, o artigo faz um levantamento de pesquisas sobre o 'conhecimento em sexualidade' e lança algumas indagações. A principal conclusão é que há uma limitação nos estudos sobre conhecimento em sexualidade do ponto de vista da G/TC e, desta forma, se faz a motivação para formação de novos(as) pesquisadores(as) em Iniciação Cientifica que operacionalizem suas investigações na perspectiva da G/TC em ES nas licenciaturas e nos cursos de formação de psicólogos.

PALAVRAS-CHAVE: Educação sexual. Conhecimento sobre sexualidade. Gnosiologia.

RESUMEN: Los conocimientos de las personas sobre la sexualidad en el área de la Educación Sexual (ES) a menudo son solo un punto de partida para la investigación o la formación continua de los docentes, pero las propuestas para la transformación en teoría son casi inexistentes. , posterior construcción del currículum en ES, de este conocimiento. En vista de esto, el presente artículo, con metodología bibliográfica, pretende proponer el referencial de gnosiología / teoría del conocimiento $(G / T C)$, enfatizando las diferentes formas de conocer la sexualidad. Después de una breve referencia en $G / T C$, el artículo investiga la investigación sobre el "conocimiento sobre la sexualidad" y plantea algunas preguntas. La conclusión principal es que existe una limitación en los estudios sobre el conocimiento sobre la sexualidad desde el punto de vista de G / CTy, por lo tanto, existe una motivación para capacitar a nuevos investigadores en Iniciación Cientifica para que sus investigaciones sean operativas. perspectiva de G / TC en educación superior en cursos de pregrado y psicología.

PALABRAS CLAVE: Educación sexual. Conocimiento sobre sexualidade. Gnosiología.

\footnotetext{
${ }^{1}$ Universidade Federal de Jataí (UFJ), Jataí - GO - Brasil. Docente e Pesquisador do Curso de Pedagogia. Doutorado em Educação Escolar (UNESP). Unidade Acadêmica Especial de Educação. ORCID: https://orcid.org/0000-0003-1693-4804. E-mail: claudionorsil@gmail.com
} 
ABSTRACT: People's knowledge about sexuality in the area of Sexual Education (SE) is often just a starting point for research or continuing education for teachers, but almost nonexistent are the proposals for transformation into theory, and later construction of curriculum in SE, of this knowledge. In view of this, the present article, with bibliographic methodology, intends to propose the referential of gnosiology/theory of knowledge (G/TK), emphasizing the different ways of knowing about sexuality. After a brief reference in $G / T K$, the article surveys research on "knowledge about sexuality" and raises some questions. The main conclusion is that there is a limitation in the studies on knowledge about sexuality from the point of view of G/TK and, thus, the motivation for the formation of new researchers in Scientific Initiation is made to operationalize their investigations in the perspective of $G / T K$ in higher education in undergraduate and psychologist formative courses.

KEYWORDS: Sex education. Knowledge about sexuality. Gnosiology.

\section{Introdução}

A pergunta deste artigo: como se conhece sobre sexualidade? Ou, como está a produção científica, na contemporaneidade, sobre o conhecimento em sexualidade humana? A segunda parte da problemática: como a gnosiologia/teoria do conhecimento (G/TC) pode contribuir para o status da produção científica sobre o conhecimento em sexualidade, na Educação Sexual, no formato de currículo para a educação escolar? O que revelam os estudos mais recentes sobre o saber em sexualidade que permita a construção de um quadro gnosiológico que encaminhe uma teoria do conhecimento em Educação Sexual?

Nesta pergunta, se estrutura um referencial sobre gnosiologia/teoria do conhecimento (G/TC), um termo em muito desuso, muito raro de se encontrar, e, às vezes confundido com Epistemologia da Ciência, mas, é recuperado neste artigo em uma pesquisa muito inicial.

A pergunta desta investigação também é pensada para ser proposta aos estudos, na atualidade, sobre o conhecimento em sexualidade, em como se conhece sobre sexualidade, os 'antecedentes' deste conhecimento(s), ou seja, sua origem e seu processo. Dito de outra forma, busca-se neste artigo, incentivar investigações gnosiológicas que possam se transformar em currículo para a Educação Sexual.

Com o referencial na gnosiologia/teoria do conhecimento, pretende-se encontrar e elaborar indagações que direcionem para a Educação Sexual, pesquisas e estudos, de iniciação científica, na graduação, que se debrucem sobre o tema da construção de conhecimento, que se dá (ou deveria se dar) de diferentes formas, não apenas no formato científico/escolar ou apenas escolar, no sentido de 'coleta fria' de dados, dados 'pontuais', por exemplo, o que é sexualidade.

Por isso, a configuração cidadã e, portanto, política desta proposta textual, é extremamente desafiadora; se buscam a origem e os processos de construção do saber em 
sexualidade que possam ser transformados em currículo, em educação escolar e que nascem dos diversos espaços de socialização e também de indexação ou localização de informações sobre sexualidade, da família, da religião ao computador ou celular.

De metodologia bibliográfica (SAMPIERI; COLLADO; LÚCIO, 2006) o estudo empreendido aqui é de natureza teórica, tanto na construção dos referenciais em gnosiologia/teoria do conhecimento para a Educação Sexual, como também, no levantamento de pesquisas que, na atualidade, tratam do conhecimento em Educação Sexual. E, com o aporte dado por estes autores, permite a apresentação de lacunas nas pesquisas, origem de definições e conceitos e encaminhamentos de pesquisas que possam ser efetuadas, neste texto tem-se discussões e uma conclusão, com algumas indagações para a temática da teoria do conhecimento em Educação Sexual.

Localizaram-se mais de cem (100) artigos em periódicos, no Google Acadêmico, como empreendimento inicial da temática, que revelou dentre outras relevantes considerações, o fato de que não se preocupam na forma como se constrói a sexualidade na infância e, em nenhum momento, os estudos colocam como se conhece sobre sexualidade, uma questão fundante e inicial para a gnosiologia/teoria do conhecimento. Está ausente o encaminhamento dos estudos para uma linha teórico-gnosiológica na área da Educação Sexual, sendo que, grande parte dos 'achados' são quase inteiramente da área da saúde, particularmente, a Enfermagem.

Para defender os argumentos por uma G/TC em Educação Sexual, levando-se em conta a problemática do estudo, apresenta-se na seção seguinte um breve referencial que é muito incipiente e incompleto, no sentido de que existem várias frentes teóricas para o estudo da G/TC. Depois, se detalha os 'achados' do levantamento e se apresentam as indagações para a contemporaneidade a se propor à Educação Sexual, seus pesquisadores(as), principalmente, os iniciantes, dos cursos de licenciatura e formação de psicólogos, a pensarem pesquisas no âmbito da gnosiologia para geração de teorias na área; a busca de identificar, fora dos espaços escolares e de currículo, um corpus teórico em 'lugares' de conhecimento dos mais diversos, sobre a sexualidade humana, não necessariamente, escolares ou científicos. $\mathrm{Na}$ conclusão, se encaminham algumas motivações aos novos(as) pesquisadores(as) em Educação Sexual em projetos de Iniciação Científica na graduação.

\section{Gnosiologia/Teoria do Conhecimento (TC)}

Gnosiologia parece uma palavra sem uso e em pleno desuso conceitual nos artigos, dissertações e teses em Educação e Ciências Sociais. Talvez estejamos mais acostumados com 
a expressão 'Teoria do Conhecimento' (TC). E, ademais, há muita confusão entre TC e Epistemologia, TC e Epistemologia da Ciência; TC e Filosofia da Ciência.

Chauí (2000) já nos deixa explícito, bem como Castanõn (2007), que TC é o ato de conhecer do humano, o processo do pensamento; descreve ou incorpora todos os tipos de formas de conhecer, de construir conhecimento. Já Epistemologia passou a ser sinônimo de Filosofia da Ciência e, desta forma, trata somente do conhecimento científico, por isso, Epistemologia da Ciência.

Stanislavs Ladusãns (1992, p. 32) define gnosiologia como “[...] uma ciência filosófica num sentido rigoroso, isto é, ela é um conjunto sistemático de conhecimentos, referentes às últimas causas e condições necessárias do conhecimento da verdade [...]”.

Organizando esta máxima, na forma da definição anterior e considerando a Gnosiologia como Teoria do Conhecimento (como se conhece e quais as formas de se conhecer ou 'saber algo') é possível pontuar os elementos filosóficos da Gnosiologia/TC, quais sejam: pensar tudo que possa estar na relação sujeito (o humano) e objeto (o que se conhece ou se passa a conhecer; a realidade). E, desta relação, pontuar também: a) qual a origem do conhecimento ou como se passa a conhecer; b) como se dá o processo de consolidação deste conhecimento ou saber; c) como se chega à verdade deste conhecimento - ponto último ou máximo, no interior da Filosofia. Esse exercício inicial foi apresentado de diferentes formas e por diferentes filósofos, inicialmente, se destacam René Descartes (1596-1650), John Locke (1632-1704) e Immanuel Kant (1724-1804): racionalistas (razão), de um lado, empiristas (sentidos/vivências), de outro; realismo versus idealismo como correntes antagônicas.

Neste artigo se propõe pensar esta relação sujeito/objeto, na forma de pergunta: como se conhece sobre sexualidade? Como o estudo sistemático deste conhecer pode se transformar em teoria do conhecimento, o próprio exercício da gnosiologia e, por conseguinte, em currículo da educação escolar em Educação Sexual? Este, um estudo, ainda inicial e fase de primeiras reflexões.

Gnosiologia/Teoria do Conhecimento (G/TC) é o ato de conhecer ou como se conhece. Transposto para esta pesquisa se propõe a elaboração, a partir da gnosiologia (teoria do conhecimento), se pensar para o elencamento de pesquisas sobre o conhecimento em sexualidade, uma metodologia com os fundamentos gnosiológicos aplicáveis à Educação Sexual. Se propõe a construção de um currículo de Educação Sexual que nasça da G/TC, ou seja, elencar e identificar a origem, o processo de construção, a consolidação e a modificação (se ela existe ou não) deste(s) conhecimento(s). A origem do conhecimento não é apenas 
escolar, não é apenas científica. Pode ser midiático, pode ser por convivência, pode se dado pela religião, etc. Esta é a defesa deste artigo.

Esta área da Filosofia apresenta várias correntes de pensamento. Elegeremos alguns teóricos para esta proposta de pesquisa, por exemplo, o ciclo gnosiológico freireano (FREIRE, 1986; 1996; 2007), a gnosiologia pluridimensional de Stanislavs Ladusãns (1992) e a gnosiologia de Steiner (2004). São apenas algumas possibilidades e encaminhamentos.

Paulo Freire apresenta-nos o ciclo gnosiológico (ciclo de ensinar e aprender), ou o ciclo do conhecimento como prática pedagógica, sob as dimensões epistemológicas, históricofilosóficas, político-ideológicas, comunicativa e dialógica, ética e estética, pedagógico-cultural e institucional e de gestão. Chamaremos neste artigo de Ciclo Gnosiológico de Paulo Freire e representaremos pela sigla 'CGPF'.

Para Paulo Freire é a curiosidade do sujeito que permite construir o conhecimento sobre o objeto. E isso se faz pela criticidade (FREIRE, 1996), pelo distanciamento, em que, uma sequência de ações são operacionalizadas pelo sujeito sobre o objeto ou, dito de outra forma, o sujeito 'incide' sobre o objeto sua observação, constrói a delimitação necessária na observação e aproximação, faz o 'cercamento' para comparar, perguntar, 'vasculhar'.

Sobre a origem do conhecimento, ou a problemática gnosiológica crítica, na Gnosiologia Pluridimensional de Stanislavs Ladusãns (1992), na 'Primeira Investigação', sua proposta crítica da teoria do conhecimento é a origem, de onde vem e como se construiu tal conhecimento. Qual o problema ou problemática deste conhecimento, qual seu método para consolidação e como é dada a resposta para este conhecimento.

Sobre estas questões, o autor, utilizando-se de alguns momentos de um viés teológico, vai chegar à questão filosófica da gnosiologia, defendendo a existência de um homem 'préfilosófico' que pergunta sobre o mundo em que vive. Um homem que pergunta sobre o conhecimento, se é válido ou não, mas, ainda é um ser pré-filosófico. Esta é a gnosiologia que se busca aqui. Pois, o homem 'filosófico', na acepção de Stanislavs Ladusãns (1992) utiliza-se da Filosofia.

Mas estamos em busca de identificação deste 'pré-filósofo', ainda que, em nossa proposta, o conhecimento filosófico é um tipo de conhecimento no interior da gnosiologia. Mas este pré-filósofo que nos interessa, concernente ao conhecimento sobre sexualidade, tem a seguinte questão central: qual a validade ou o valor do conhecimento sobre sexualidade humana? Existe a verdade sobre isso? Qual a sistematização ideal para validade deste conhecimento? 
A continuidade de suas questões é o fim de toda proposta gnosiológica, qual seja, o conhecimento da verdade, a validação de todo o conhecimento (STANISLAVS LADUSÃNS, 1992).

A solução ao problema gnosiológico: o sujeito do conhecimento é o eu. Esta é a consciência intelectual. Esta consciência soluciona a questão do conhecer. Autorreflexão, experiência. O sujeito constata, descreve, analisa fidedignamente e, finalmente, faz o exame crítico deste conhecimento. Daqui Stanislavs Ladusãns (1992) retira a definição de gnosiologia pluridimensional - resposta ao problema crítico sobre o conhecer: "[...] trata do valor cognoscitivo real da ciência humana integral e dos limites do nosso saber [...]" (STANISLAVS LADUSÃNS, 1992, p. 33).

Terminologias postas como sinônimos para a gnosiologia: crítica (krinein: julgar); na ética (noetikós, inteligente; leis gerais) e, “[...] Teoria do Conhecimento - do grego "theoría", um exame atencioso, o estudo - que trata do conhecimento filosoficamente sob o aspecto de seu valor real e dos limites" (STANISLAVS LADUSÃNS, 1992, p. 33).

Na obra de Steiner (2004), apoiado em Goethe, o conhecimento é considerado como algo ilimitado, ou seja, não há limites para o ser humano; seu poder de reflexão e de pensar é algo extraordinário. O poder imaginativo e curioso. Steiner amplia a teoria do conhecimento, ao propor a 'ilimitação' do saber, ao construir sua corrente de pensamento gnosiológico ou uma teoria de conhecimento a partir de Goethe. Rudolf Steiner (1861-1925), filósofo e educador, inaugura a antroposofia, que, em sua proposta, coloca a integração da objetividade e da subjetividade no processo de conhecer.

Conhecer, portanto, é a verdade que se busca sobre o objeto pensado pelo sujeito. A pergunta gnosiológica central é: o que se pode conhecer e estipular como verdade? Então, o sujeito é a consciência, a mente, em busca da verdade.

São muitos outros teóricos do conhecimento. Aqui se apresentam apenas três, mas que, de qualquer forma, podem ser referências iniciais em nossa construção teórica para se pensar uma gnosiologia à Educação Sexual que não nasça na escola, mas no dia a dia das pessoas, nas suas vozes e vivências; nasça 'nos' e 'entre' os 'homens da rua' como dizem Berger e Luckmann (2001); nasçam das realidades sociais, culturais, como nos apresenta Parker e Aggleton (2007) e Bozon (2004) ao falar da 'sociologia da sexualidade'.

Entre os autores da área da Educação Sexual, para nossas reflexões gnosiológicas que serão lançadas sobre o levantamento apresentado na próxima seção, destacamos Figueiró (1996; 2010) que, ao tratar do 'Saber em Educação Sexual' em seus textos nos ajuda a justificar uma Gnosiologia/Teoria do Conhecimento em Educação Sexual. Ver-se-á, sobretudo, como os 
enfoques atuais sobre conhecimentos (ou saberes) em Educação Sexual, se afastaram muito do que a autora denomina de 'primeira onda' das produções da área. Concorda-se com a autora, que os desafios à área continuam prementes e urgentes.

\section{Os estudos sobre o 'conhecimento' sobre sexualidade humana}

Esta seção ocupa-se de apresentar estudos que na contemporaneidade tratam do conhecimento em sexualidade humana.

A finalidade deste cenário de levantamento de trabalhos publicados em periódicos, eventos científicos, dissertações, teses, etc., são também os próprios temas na contemporaneidade que ajudam a construir as indagações sobre como se constrói ou se constroem, saberes sobre sexualidade humana e, que, nas considerações finais, acabam por incorporar os encaminhamentos da presente pesquisa, ao lançar o desafio para pesquisas de iniciação científica em licenciaturas e cursos de formação de psicólogos.

Sobre as indagações, resultante do breve referencial em gnosiologia/teoria do conhecimento e o levantamento efetuado na pesquisa, propriamente, se organizam uma estruturação de pesquisas, em Educação Sexual, que se apoiem na Gnosiologia/Teoria do Conhecimento, na geração de teorias, teorizações.

Foram acessados mais de 100 trabalhos, sob o descritor "conhecimento em sexualidade". Incluindo citações, no período de 2018 a 2019, para um levantamento inicial.

Estes trabalhos apresentados no Quadro 1, se entrelaçam para uma proposta em gnosiologia/teoria do conhecimento, de forma parcial. Faltam muitos elementos, o principal, talvez, seja a origem dos conhecimentos produzidos pelos adolescentes, pelos idosos, pelos professores, pelos profissionais de saúde, enfim. Apoiados em Freire (1996; 2002; 2007) estes 'informativos' em sexualidade humana deveriam passar pelo crivo das dimensões políticas, estéticas, históricas e sociais, enfim. É, justamente, nessa acepção, que esta pesquisa é pensada, conforme apresentado na problemática e se configuram como limitações da pesquisa.

Vamos ao Quadro 1 que apresenta Eixos e alguns referenciais extraídos do levantamento. 
Quadro 1 - Eixos e respectivas referências

\begin{tabular}{|c|c|}
\hline $\begin{array}{l}\text { EIXO 1: Conhecimento em } \\
\text { sexualidade ligado à saúde: doenças, } \\
\text { infecções } \\
D S T \text {, HIV/AIDS } \\
\text { Infecções } \\
\text { Oficinas de prevenção } \\
\text { Conhecimentos sobre sexualidade entre } \\
\text { adolescentes/jovens universitários, } \\
\text { professores, profissionais da Saúde e } \\
\text { outras áreas. } \\
\text { Anticoncepcionais }\end{array}$ & $\begin{array}{l}\text { Cruz et al., (2018) } \\
\text { Fernandes et al., (2018) } \\
\text { Carvalho, Pinto e Santos (2018) } \\
\text { Spíndola (2018) } \\
\text { Santos et al., (2018) } \\
\text { Silva (2018) } \\
\text { Silva et al., (2019) } \\
\text { Soares e Monteiro (2019) } \\
\text { Evangelista (2019) } \\
\text { Morais (2019) } \\
\text { Ferretti et al., (2019) } \\
\text { Noro, Crespi e Nóbile (2019). }\end{array}$ \\
\hline $\begin{array}{l}\text { EIXO 2: Conhecimento em } \\
\text { sexualidade em idosos(a) } \\
\text { Sexualidade entre idosos(as) }\end{array}$ & $\begin{array}{l}\text { Oliveira et al., (2018) } \\
\text { Aguiar (2018) } \\
\text { Malaquias (2018) } \\
\text { Pereira, Ponte e Costa (2018) } \\
\text { Pereira, Ponte e Costa (2018) } \\
\text { Araújo et al., (2018) }\end{array}$ \\
\hline $\begin{array}{l}\text { EIXO 3: Conhecimento } \\
\text { sexualidade ligado gravidez } \\
\text { adolescência } \\
\text { Gravidez na adolescência } \\
\text { Conhecimentos da sexualidade humana } \\
\text { durante a gravidez }\end{array}$ & $\begin{array}{l}\text { Jesus (2019) } \\
\text { Florido (2019) }\end{array}$ \\
\hline $\begin{array}{l}\text { EIXO 4: Conhecimento } \\
\text { sexualidade e a deficiência(a) } \\
\text { Sexualidade de pessoas com } S D\end{array}$ & $\begin{array}{l}\text { Maia e Vilaça (2018) } \\
\text { Souza e Abreu (2018) }\end{array}$ \\
\hline 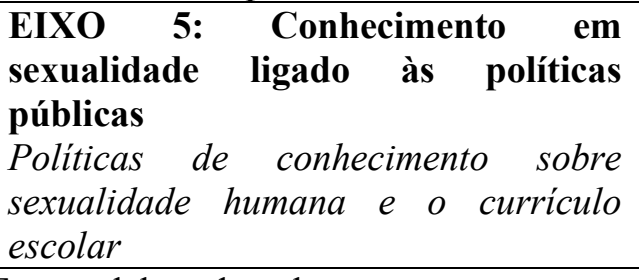 & $\begin{array}{l}\text { Carrara, França e Simões (2018) } \\
\text { Zampero et al. (2018). } \\
\text { Silva, Costa e Müller (2018) }\end{array}$ \\
\hline
\end{tabular}

Fonte: elaborado pelo autor.

Dois livros se destacam, no levantamento: 'O corpo educado: pedagogias da sexualidade', de Guacira Louro, com publicação de 2018. Este livro conta com 1373 citações, que merecem investigações para um próximo nível da pesquisa. $O$ outro livro é também da autora Guacira Louro, com edição também de 2018, com 1700 citações: 'Um corpo estranho: ensaios sobre sexualidade e teoria queer'.

Um aprofundamento desta pesquisa é avançar para as referências de citação. Muitos dos referenciais do Quadro 1 já possuem oito, cinco e até três citações. Estas citações são importantes para demarcar os impactos das pesquisas e como estão interligadas na questão dos conhecimentos em sexualidade, o que ajuda consideravelmente na construção gnosiológica proposta como metodologia neste artigo. 
O olhar gnosiológico para estes trabalhos, sob a vertente de Stanislavs Ladusãns (1992), é o apontamento do valor que este conhecimento(s) dados pelos atores investigados(as) e que refletem saberes ou os saberes do 'homem da rua' de Berger e Luckman (2001).

A pergunta dentro do ciclo gnosiológico de Paulo Freire, que seria central na busca das configurações de origem, seria o aspecto histórico e social do conhecimento.

Estão ausentes no levantamento e isso chama muito a atenção para a área da Educação Sexual os seguintes temas ou frentes:

- $\quad$ os conhecimentos sobre sexualidade advindos da família.

- $\quad$ Nas páginas online de abertura dos periódicos, a ausência de obras completas e o excesso de referenciais baseados em outros periódicos. Isto revela a falta de produções autorais mais específicas, principalmente, em Gnosiologia, um termo, quase em desuso, principalmente na Educação.

- A ênfase recai sobre o quê, o que é, mas, nunca, o como, qual o processo, interesse da gnosiologia que se propõe nesta pesquisa, para avanço do conhecimento em Educação Sexual.

- $\quad$ E a ausência, talvez, mais específica da palavra e o referencial 'gnosiologia' ou ‘teoria do conhecimento'; não aparecem em nenhum momento, ou seja, uma preocupação dos estudos sobre o que fazer com os dados, para além de análises sobre a falta de conhecimentos ou conhecimentos superficiais é o objetivo das pesquisas gnosiológicas que se está a fomentar com este artigo, sobretudo, no impulsionamento de Iniciação Científica em licenciaturas e cursos de formação de psicólogos.

Há um predomínio da área da Saúde, particularmente a Enfermagem, como a área que investiga como se conhece ou qual é o conhecimento em sexualidade, de adolescentes, jovens, idosos, profissionais de saúde. A educação vem em segundo lugar, mas com pouquíssimos trabalhos procurando investigar o conhecimento de professores em cursos de formação continuada, mas, nunca, em cursos de formação inicial, em licenciaturas. Contudo, é interessante a ênfase dos poucos trabalhos localizados, em discutir políticas públicas educacionais concernentes à Educação Sexual e o currículo.

'Saúde' aparece vinte e quatro (24) vezes no levantamento, seguido de Escola (10 vezes) e Educação Sexual, apenas duas vezes. A baixa frequência da palavra 'Educação Sexual' é o principal sinal de alerta nos achados. Educação, apenas duas vezes. 
A palavra 'sexualidade' aparece 54 vezes, seguida de 'conhecimento' com 45 vezes e 'conhecimentos' (no plural) 11 vezes, o que nos leva a consideração de que 'conhecimento' nossa principal palavra-chave na pesquisa, aparece 56 vezes. Gênero, apenas 11 vezes.

Assim, como nos estudos de Figueiró (2010) os conhecimentos sobre sexualidade advindos da abordagem religiosa, continuam pouco explorados, o que é interessante, para os tempos atuais, em consideração, por exemplo, à ideologia de gênero e toda a resistência em se tratar do tema no espaço escolar. Por outro lado, continua em alta e, de fato, dominam os 'achados', as DST (Doenças Sexualmente Transmissíveis). Mas, a sexualidade como prazer, diferentemente dos anos 1980/1990, está completamente ausente; sexualidade parece algo negativo o que dá a entender que torna ainda mais interessante a leitura de Foucault, sobre a História da Sexualidade e a urgente necessidade de um 'contra-poder' nos discursos sobre sexualidade. Há um negativismo nos conhecimentos que são fornecidos aos adolescentes, principalmente, no Eixo 1; um espaço de produção, totalmente dominado por profissionais da saúde.

Os conhecimentos sobre sexualidade dos idosos(as) (Eixo 2) é algo recente, como resultado da ampliação da contaminação por HIV/AIDS, entre esse público, nos últimos anos. Os Eixos 3 e 4, são interessantes, sobretudo o detalhe do tema da gravidez na adolescência que apareceu como elemento deslocado do Eixo 1. Já o Eixo 5, apesar de não ser o que a princípio se busca neste trabalho, ele é importante, na medida em que posiciona o Estado quanto ao que entende e propõe em termos de conhecimentos sobre sexualidade. E, neste Eixo, a área da Educação está em destaque, como já se afirmou, anteriormente.

No conjunto, todos os Eixos lidam apenas com uma parte da gnosiologia, qual seja, a observação e a constatação, mas não a origem e os processos pelos quais esses conhecimentos se tornaram informações para descrição, análise crítica, condições para se consolidarem como 'verdade', possibilidades de comparação, etc. Nesse aspecto, tanto Paulo Freire (1986; 1996; 2007) quanto Stanislavs Ladusãns (1992) podem ser utilizados para se construir uma G/TC em Educação Sexual, com estes dados coletados na pesquisa para falar da origem e do processo de 'fixação' de conhecimentos sobre sexualidade humana de adolescentes, jovens, adultos.

A G/TC ajudaria em primeiro lugar em permitir que nós, pesquisadores(as) iniciantes e não iniciantes, a fugirmos da ciência, do currículo escolar (se possível), e nos direcionarmos para a descoberta destas fontes do conhecer obtida sob diversas pelas crianças, adolescentes, jovens, adultos e idosos, pais, professores, psicólogos, enfermeiros, médicos. A G/TC em Educação Sexual é, portanto, serem pensadas as formas diversas em como estas pessoas constroem seus conhecimentos em sexualidade. A gnosiologia se debruçaria na origem destes 
conhecimentos, os processos pelos quais eles se estabeleceram e, numa etapa posterior, como se modificam ou são possíveis ser modificadas, posturas, falas, ações, etc.

Que base, em G/TC, se pode empreender para que em um recorte cultural e o mais afastado do currículo escolar possível se identifique processos pelos quais se conhece sobre sexualidade humana? Talvez, se começar pela escolha e definição de uma corrente gnosiológica, dentre as muitas possíveis, como o ciclo gnosiológico de Paulo Freire ou outra. O principal cuidado: não se tratam de epistemólogos(as) da ciência, mas autores e autoras da Filosofia que seguem as diretrizes da gnosiologia/teoria do conhecimento, tal como neste breve referencial, apresentado neste artigo.

Estas são as indagações que encaminham o final desta pesquisa inicial que traz uma palavra e uma categoria meio em desuso, a gnosiologia, para uma centralidade na construção de um projeto de pesquisa para iniciantes de licenciaturas e cursos de Psicologia. Quais são essas indagações na contemporaneidade que tem por base a G/TC?

1) Por que o conhecimento sobre sexualidade deve residir apenas nas questões relativas às DST e o destaque para o HIV/AIDS?

2) Por que esse conhecer sobre a sexualidade repousa apenas no informativoprevenção, como se sexualidade estivesse apenas para a relação sexual e a questão da doença?

3) O conhecer sobre sexualidade se dá apenas na escola e em projetos da área da saúde? E o espaço educacional dos educadores sexuais formados em licenciaturas, sobretudo a Pedagogia?

4) Por que as famílias estão fora dos estudos relativos ao tema? A família não 'informa' ou 'forma' para a sexualidade? E porque as crianças estão fora? A religião não educa sexualmente?

5) De que forma pode ser pensada uma proposta gnosiológica, portanto, de teoria do conhecimento, que supere o preventivo aos adolescentes e a negatividade de apresentar a sexualidade como um problema de saúde pública? Mais importante: uma proposta gnosiológica para fora do espaço escolar e mais abrangente para os espaços sociais, principalmente, movimentos sociais e ações dos partidos políticos mais progressistas e voltados para as formações de base política e de empoderamento de gênero? De que forma 'fugir' de relatos que já se sabe o resultado para transformar dados de informação em teorias de conhecimento em Educação Sexual para serem transpostas ao currículo escolar? 
Tomando, inicialmente, como modelo teórico, o Ciclo Gnosiológico de Paulo Freire (CGPF), uma (possível) metodologia para se pensar, por exemplo, estas mesmas pesquisas, como continuidades ou reinícios, como exercício aos iniciantes em pesquisa, na área da Educação Sexual, sugere-se a ênfase na origem e no processo de construção do conhecimento, do saber sobre a sexualidade. O objetivo é/seria, então, o de se organizar a origem, os processos, a consolidação e as mudanças de conhecimento(s) em sexualidade. Acredita-se que esse exercício é mais eficiente ou torna-se efetivo na medida em que contribui, também, para se entender novas estratégias de desconstrução de preconceitos, discriminações, etc.

Na construção das dimensões do CGPF já se estará neste exercício de configuração gnosiológica, de teoria do conhecimento em Educação Sexual. Restaria, a orientação, com pesquisadores(as) experientes, para a consolidação de um currículo em Educação Sexual.

Outras perspectivas ou correntes gnosiológicas, como as citadas neste artigo, necessitariam de orientações mais especializadas, sobretudo, em parcerias com filósofos(as) que refletem sobre as fronteiras da G/TC com Filosofia da Ciência, Epistemologia da Ciência.

\section{Considerações finais}

As indagações apontadas no final da seção anterior são ideias iniciais que ajudam a retomar o sentido da gnosiologia/teoria do conhecimento e organizá-la no âmbito da Educação Sexual.

Há limitações neste estudo. A principal é a necessidade de uma ampliação das fontes referenciais, para se constatar as origens e formas de construção dos conhecimentos pelos quais as pessoas 'conhecem' sobre sexualidade. É necessário encontrar na literatura, como acontecem e como vêm se apropriando ou se construindo os conhecimentos sobre sexualidade, para se organizar reflexões aos novos(as) pesquisadores(as) em Iniciação Científica e, sobretudo, motivá-los para estas investigações, de natureza gnosiológica. Contudo, essa sondagem inicial permitiu o encaminhamento de investigações sob o caráter gnosiológico na área da Educação Sexual.

A temática necessita, assim, de continuidades e aprofundamentos, sobretudo a construção ou escolha de uma metodologia teórica e empírica gnosiológica/TC que elabore um corpus discursivo/expositivo sólido em Educação Sexual, para ser transposto ao currículo escolar, expandindo o conhecimento(s) em sexualidade humana para os espaços "fora" da escola para, somente depois, para ela retornar, na forma de currículo e com base gnosiológica, na forma de teoria do conhecimento em Educação Sexual. 
A gnosiologia e a produção de conhecimento em Educação Sexual precisam ser ampliadas para fora dos espaços (unicamente) escolares em que são 'capturadas' informações, representações sobre a sexualidade. Pela proposta aqui empreendida é a base gnosiológica primeiro e o currículo depois. Neste sentido, falar apenas dos adolescentes - nada se fala sobre crianças e jovens; com jovens, bem pouco - é muito limitado e, de alguma forma, compreender esse "saber" do idoso(a) sobre sexualidade merece um olhar dos pesquisadores(as) da área da Educação Sexual. De modo amplo, se precisa pensar gnosiologicamente/teoricamente sobre o modo como esses saberes se constroem socialmente e historicamente, pois, são omitidos nas investigações e pouco se vê retornar como teoria na área da Educação Sexual.

Estamos diante de um desafio para a área, qual seja, ampliarmos os espaços formativos em saberes 'de' e 'sobre' a sexualidade humana, nas diversas instâncias sociais formativas e se aposta num projeto antropológico de investigação, a princípio, e, o quanto se puder, o mais afastado da educação escolar para este projeto - paradoxo? - esse um desafio ainda mais interessante aos pesquisadores(as), sobretudo, em Iniciação Científica, em cursos de licenciaturas e formação de psicólogos: saberes, conhecimentos em sua origem e processos de construção/consolidação, transformados em teoria, teorizações, em Educação Sexual.

\section{REFERÊNCIAS}

AGUIAR, R. B. Conhecimento e atitudes sobre sexualidade de idosos infectados pelo HIV assistidos em serviços de referência. 2018. 121 f. Dissertação (Mestrado em Saúde Coletiva) - Universidade Federal de Pernambuco, Recife, 2018. Disponível em: https://attena.ufpe.br/handle/123456789/30451. Acesso em: 11 abr. 2020.

ARAÚJO, H. S. P. et al. Sexualidade da pessoa idosa na visão de enfermeiros: uma revisão interativa. In: CONGRESSO BRASILEIRO DE CIÊNCIAS DA SAÚDE, 3., 2018, Campina Grande. v. 1. Anais [...]. Campina Grande, PB, 2018. Disponível em: https://editorarealize.com.br/revistas/conbracis/trabalhos/TRABALHO_EV108_MD1_SA4_I D1133_20052018200704.pdf. Acesso em: 11 abr. 2020.

BERGER, P. L.; LUCKMANN, T. A construção social da realidade. 20. ed. Petrópolis, RJ: Vozes, 2001.

BOZON, M. Sociologia da sexualidade. Rio de Janeiro: Editora FGV, 2004.

CARRARA, S.; FRANÇA, I. L.; SIMÕES, J. A. Conhecimento e práticas científicas na esfera pública: antropologia, gênero e sexualidade. Revista de Antropologia, v. 61, n. 1, p. 71-82, 2018. Disponível em: http://www.revistas.usp.br/ra/article/view/145514. Acesso em: 11 abr. 2020. 
CARVALHO, O.; PINTO, R. G. S.; SANTOS, M. S. Conhecimento sobre as infecções sexualmente transmissíveis por estudantes adolescentes de escolas públicas. Adolesc. Saúde, Rio de Janeiro, v. 15, n. 1, p. 7-17, jan./mar. 2018. Disponível em:

http://www.adolescenciaesaude.com/detalhe_artigo.asp?id=703. Acesso em: 11 abr. 2020.

CASTAÑON, G. Introdução à epistemologia. São Paulo: EPU, 2007.

CHAUÍ, M. Convite à filosofia. São Paulo: Ed. Ática, 2000.

CRUZ, L. Z. et al. Conhecimento dos adolescentes sobre contracepção e infecções transmissíveis. Adolesc. Saúde, Rio de Janeiro, v. 15, n. 2, p. 7-18, abr./jun. 2018. Disponível em: http://www.adolescenciaesaude.com/detalhe_artigo.asp?id=714\&idioma=English. Acesso em: 11 abr. 2020.

EVANGELISTA, A. R. (2019). Sexualidade de idosos: conhecimento/atitude de enfermeiros da Estratégia Saúde da Família. Revista da Escola de Enfermagem da USP, v. 53, 2019. Disponível em: http://www.scielo.br/scielo.php?pid=S008062342019000100454\&script=sci_arttext\&tlng=pt. Acesso em: 11 abr. 2020.

FERNANDES, V. R. et al. Jovens universitários e o conhecimento acerca das infecções sexualmente transmissíveis. Esc. Anna Nery, v. 22, n. 2, 21 maio 2018. Disponível em: https://www.scielo.br/scielo.php?script=sci_abstract\&pid=S1414$81452018000200208 \& \operatorname{lng}=$ pt\&nrm=iso. Acesso em: 11 abr. 2020.

FERRETTI, E. et al. Promovendo conhecimento: infecções sexualmente transmissíveis (ISTS) em uma unidade do Exército Brasileiro de Fronteira. Anais do $1^{\circ}$ Salão Internacional de Ensino, Pesquisa e Extensão da UNIPAMPA: Salão de Extensão, v. 11, n. 3, 2019. Disponível em:

https://periodicos.unipampa.edu.br/index.php/SIEPE/article/view/87576. Acesso em: 11 abr. 2020 .

FIGUEIRÓ, M. N. D. A produção teórica no Brasil sobre Educação Sexual. Cadernos de Pesquisa, n. 98, 1996. Disponível em:

http://publicacoes.fcc.org.br/ojs/index.php/cp/article/view/795. Acesso em mar. 2020.

FIGUEIRÓ, M. N. D. Educação Sexual: retomando uma proposta, um desafio. 3. ed. revista e atualizada. Londrina: Eduel, 2010.

FLORIDO, C. M. Adolescência, sexualidade e gravidez não planejada: desafios e consequências. Mundo Livre: revista multidisciplinar discente, v. 5, n. 1, p. 3-26, 2019. Disponível em: https://periodicos.uff.br/mundolivre/article/view/39974. Acesso em: $11 \mathrm{abr}$. 2020.

FREIRE, P. Pedagogia da autonomia. Saberes necessários à prática educativa. 34. ed. São Paulo: Paz e Terra, 1996.

FREIRE, P. Ação cultural para a liberdade e outros escritos. 12. ed. Rio de Janeiro: Paz e Terra, 2007. 
FREIRE, P.; SHO, I. Medo e ousadia: o cotidiano do professor. 11. ed. Rio de Janeiro: Paz e Terra, 1986.

JESUS, D.; MESQUITA, M.; PAULA, I.; ESTEVES, D.; SANTOS, M.; MARTINS, M.; CORREIA, T. I. G. Sexualidade na gravidez. In: ENCONTRO DE JOVENS INVESTIGADORES, 6., 2019, Bragança. Anais [...]. Bragança, Portugal: Instituto Politécnico de Bragança, 2019. Disponível em: https://bibliotecadigital.ipb.pt/handle/10198/20430. Acesso em: 11 abr. 2020.

MAIA, A. C. B.; VILAÇA, T. Conhecimento de professores/as sobre sexualidade e deficiências. In A. Peixoto, J. Oliveira, J. Gonçalves, L. Neves, \& R. Cruz (Eds.), Educação em Ciências em múltiplos contextos. In: ENCONTRO NACIONAL DE EDUCAÇÃO EM CIÊNCIAS, 17.; SEMINÁRIO INTERNACIONAL DE EDUCAÇÃO EM CIÊNCIAS, 1. 2018, Viana do Castelo. Anais [...]. Viana do Castelo, Portugal: Instituto Politécnico de Viana do Castelo, p. 428-436, 2018. Disponível em:

https://repositorium.sdum.uminho.pt/handle/1822/58114. Acesso em: 11 abr. 2020.

\section{MALAQUIAS, B. S. S. Atitudes e conhecimento de enfermeiros de diferentes níveis} assistenciais em relação à sexualidade do idoso. 2018. 100 f. Dissertação (Mestrado em Atenção à Saúde) - Universidade Federal do Triângulo Mineiro, Uberaba, 2018.

MORAIS, P. P. S. Formação pedagógica e conhecimento sobre sexualidade. 2019. Monografia (Trabalho de Conclusão do Curso de Pedagogia) - Universidade Federal Rural de Pernambuco, Recife, 2019. Disponível em:

https://www.repository.ufrpe.br/bitstream/123456789/1861/1/tcc_paulapatriciasilvademorais. pdf. Acesso em: 11 abr. 2020.

NORO, D.; CRESPI, L.; NÓBILE, M. F. Formação docente sobre gênero e sexualidade: conhecimento, relevância, caminhos. In: ENCONTRO NACIONAL DE PESQUISA EM EDUCAÇÃO EM CIÊNCIAS, 12., 2019, Natal. Anais [...]. Natal, RN: Universidade Federal do Rio Grande do Norte, jun. 2019. Disponível em: http://abrapecnet.org.br/enpec/xiienpec/anais/resumos/1/R0059-1.pdf. Acesso em: 11 abr. 2020.

OLIVEIRA, D. V. et al. Conhecimento sobre sexualidade em idosas fisicamente ativas. Revista Ártemis, v. 26, n. 1, p. 271-282, 2018. Disponível em: https://periodicos.ufpb.br/index.php/artemis/article/view/37534. Acesso em: 11 abr. 2020.

PARKER, R.; AGGLETON, P. Culture, society and sexuality: a reader. 2. ed. New York: Routledge, 2007.

PEREIRA, D.; PONTE, F.; COSTA, E. Preditores das atitudes negativas face ao envelhecimento e face à sexualidade na terceira idade. Análise Psicológia, Lisboa, v. 36, n. 1, 2018. Disponível em: http://www.scielo.mec.pt/scielo.php?pid=S087082312018000100003\&script=sci_arttext\&tlng=en. Acesso em: 11 abr. 2020.

SAMPIERI, R. H.; COLLADO, C. F.; LÚCIO, M. D. P. B. Metodologia. São Paulo: McGraw-Hill, 2006.

SANTOS, C. M. A. et al. Conhecimentos, atitudes e prática de homens sobre infecções sexualmente transmissíveis. Cogitare Enfermagem, v. 1, n. 23, 2018. Disponível em: 
http://www.saude.ufpr.br/portal/revistacogitare/wp-content/uploads/sites/28/2018/09/54101222679-1-PB.pdf. Acesso em: 11 abril 2020.

SILVA, D. R. Q.; COSTA, Z. L. S.; MÜLLER, M. B. C. Gênero, sexualidade e políticas públicas de educação. Educação, revista quadrimestral, Porto Alegre, v. 41, n. 1, p. 49-58, jan./abr. 2018. Disponível em:

https://www.redalyc.org/jatsRepo/848/84857099008/84857099008.pdf. Acesso em 15 abr. 2020 .

SILVA, M. C. N. Sexualidade: o conhecimento do corpo como educação emancipatória. In: SEMINÁRIO CORPO, GÊNERO E SEXUALIDADE, 7., 2018, Rio Grande. Anais [...]. Rio Grande, RS: Universidade Federal do Rio Grande, set. 2018. Disponível em:

https://seminariocorpogenerosexualidade.furg.br/images/arquivo/332.pdf. Acesso em: 11 abr. 2020.

SILVA, S. et al. Diagnóstico do conhecimento dos adolescentes sobre sexualidade. Revista Ata Paulista de Enfermagem, 2019. Disponível em:

https://bdigital.ufp.pt/handle/10284/8189Acesso em: 11 abril 2020.

SOARES, Z. P.; MONTEIRO, S. S. Formação docente sobre gênero e sexualidade: conhecimento. Educar em Revista, Curitiba, v. 35, n. 73, p. 287-305, jan./fev. 2019. Disponível em: http://www.scielo.br/scielo.php?script=sci_arttext\&pid=S010440602019000100287. Acesso em: 11 abr. 2020.

SPÍNDOLA, T. Práticas sexuais, conhecimento e comportamento dos universitários em relação às infecções sexualmente transmissíveis. Revista de Pesquisa Cuidado é Fundamental, v. 11, n. 5, 2019. Disponível em:

http://ciberindex.com/index.php/ps/article/view/P11351141. Acesso em: 11 abr. 2020.

STANISLAVS LADUSÃNS, S.J. Gnosiologia pluridimensional: fenomenologia do conhecimento e gnosiologia crítica geral. São Paulo: Loyola, 1992.

STEINER, R. O método cognitivo de Goethe: linhas básicas para uma gnosiologia da cosmovisão goethiana. São Paulo: Antroposófica, 2004.

ZAMPERO, A. F.; LEITE, C. M.; GIANGARELLI, C.; BERGAMO, M. C. A temática sexualidade nas propostas curriculares no Brasil. Revista Ciências \& Ideias, v. 9, n. 1, p. 102-114, 2018. Disponível em:

https://revistascientificas.ifrj.edu.br/revista/index.php/reci/article/view/783. Acesso em: 11 abr. 2020. 


\section{Como referenciar este artigo}

SILVA, C. R. da. O conhecimento sobre sexualidade - por uma gnosiologia (teoria do conhecimento) em educação sexual: algumas indagações. Doxa: Rev. Bras. Psico. e Educ., Araraquara, v. 22, n. 1, p. 66-82, jan./jun., 2020. e-ISSN: 2594-8385. DOI: https://doi.org/10.30715/doxa.v22i1.13598

Submetido em: $26 / 12 / 2019$

Revisões requeridas em: 08/02/2020

Aceito em: 30/04/2020

Publicado em: 01/06/2020 